\title{
Enhanced extraction efficiency of fluorescent SiC by surface nanostructuring
}

\author{
Ou, Yiyu; Jokubavicius, Valdas; Yakimova, Rositza; Syväjärvi, Mikael ; Ou, Haiyan
}

Published in:

CLEO Technical Digest

Publication date:

2012

Document Version

Publisher's PDF, also known as Version of record

Link back to DTU Orbit

Citation (APA):

Ou, Y., Jokubavicius, V., Yakimova, R., Syväjärvi, M., \& Ou, H. (2012). Enhanced extraction efficiency of fluorescent SiC by surface nanostructuring. In CLEO Technical Digest (pp. JW3L.8). Optical Society of America.

\section{General rights}

Copyright and moral rights for the publications made accessible in the public portal are retained by the authors and/or other copyright owners and it is a condition of accessing publications that users recognise and abide by the legal requirements associated with these rights.

- Users may download and print one copy of any publication from the public portal for the purpose of private study or research.

- You may not further distribute the material or use it for any profit-making activity or commercial gain

- You may freely distribute the URL identifying the publication in the public portal

If you believe that this document breaches copyright please contact us providing details, and we will remove access to the work immediately and investigate your claim. 


\title{
Enhanced extraction efficiency of fluorescent SiC by surface nanostructuring
}

\author{
Yiyu Ou, ${ }^{1, *}$ Valdas Jokubavicius, ${ }^{2}$ Rositza Yakimova, ${ }^{2}$ Mikael Syväjärvi, ${ }^{2}$ and Haiyan \\ Ou ${ }^{1}$ \\ ${ }^{1}$ Department of Photonics Engineering, Technical University of Denmark, Lyngby DK-2800, Denmark \\ ${ }^{2}$ Department of Physics, Chemistry and Biology, Linköping University, Linköping SE-58183, Sweden \\ *yiyo@fotonik.dtu.dk
}

\begin{abstract}
Antireflective structures were fabricated on fluorescent $6 \mathrm{H}-\mathrm{SiC}$ for white LEDs to enhance the extraction efficiency. Average surface reflectance decreased from $22.1 \%$ to 5.1 $\%$ over a broad range, and luminescence intensity was enhanced by $41 \%$.

(C) 2011 Optical Society of America

OCIS codes: (220.4241) Nanostructure fabrication; (250.5230) Photoluminescence.
\end{abstract}

\section{Introduction}

White light-emitting diodes (LEDs) consisting of a nitride-based blue LED chip and wavelength converter material are energy-saving and environment friendly light sources for the general lighting applications. Nitrogen (N)-boron (B) doped $6 \mathrm{H}-\mathrm{SiC}$ has been proven as a high-efficiency wavelength converter with long lifetime [1-3]. Usually, the low extraction efficiency due to the internal reflection loss is a serious problem in LEDs. In the present work, we fabricated antireflective sub-wavelength structures (ARS) on the $\mathrm{N}-\mathrm{B}$ doped $6 \mathrm{H}-\mathrm{SiC}$ by reactive-ion etching (RIE) to enhance the extraction efficiency. Low surface reflection over the entire visible spectral range and consequently enhanced luminescence were achieved in the fluorescent SiC with ARS.

\section{Experiments and results}

Homoepitaxial layers of $6 \mathrm{H}-\mathrm{SiC}$ with $\mathrm{N}$ and $\mathrm{B}$ dopants were grown by Fast Sublimation Growth Process [4]. The growth process is driven by a temperature gradient created between the source, in a form of polycrystalline SiC plate, and the substrate. Boron was introduced into the epilayers by doping from the source and nitrogen incorporation was controlled by adjusting the $N_{2}$ gas pressure during the growth. The $6 \mathrm{H}-\mathrm{SiC}$ epilayers were grown on $6 \mathrm{H}-\mathrm{SiC}(0001)$ substrates with 1.4 degree off-orientation in the $[11 \overline{2} 0]$ direction at growth temperature of $1725^{\circ} \mathrm{C}$.

To fabricate the ARS on $\mathrm{SiC}$, the positive photoresist (ZEP520) was spin-coated on the $6 \mathrm{H}-\mathrm{SiC}$ sample and then prebaked on a hot plate at $160^{\circ} \mathrm{C}$ for 2 minutes. The designed mask pattern was transferred to the photoresist coating by applying the e-beam lithography (JEOL JBX9300FS). After the development, a hard mask material (Chromium) was deposited on the patterned SiC using the e-beam evaporation with a subsequent lift-off process. The dot-shaped pattern was then obtained on the hard mask. The dry etching process using $\mathrm{SF}_{6}$ and $\mathrm{O}_{2}$ precursors was carried out in the reactive-ion etching system. During the etch process, the RF-power, process pressure, and gas flow rates of the RIE were carefully chosen. Finally, the cone-shaped ARS with designed configuration (bottom diameter of $120 \mathrm{~nm}$, pitch of $170 \mathrm{~nm}$, and height of $1.2 \mu \mathrm{m}$ ) were formed on the SiC surface. An oblique-view SEM image of the ARS cone pattern is shown in the inset of Fig. 1a.

The normal reflectance cover the entire visible spectral range (370-780 nm) were measured and the results are shown in Fig. 1a. It is seen that the reflection is effectively suppressed by applying the SiC ARS. The average reflectance over the whole measured spectral range decreased from $22.1 \%$ to $5.1 \%$ and the minimum reflectance of $0.69 \%$ was observed at around $400 \mathrm{~nm}$ for the sample with ARS. Although the reflectance starts to increase at above $700 \mathrm{~nm}$, the average reflectance level even at the spectral range of the photoluminescence peak is below $6 \%$. This result indicates that the SiC ARS is an effective way to suppress the surface reflection of the fluorescent SiC sample.

The photoluminescence spectra of the samples with and without the ARS were also acquired at room temperature and the results are shown in Fig. 1b. The donor-acceptor-pair (DAP) band luminescence of the fluorescent SiC is usually broad which is a merit as a wavelength converter material. As a result, an enhanced luminescence intensity as well as the same spectral profile are expected after introducing the $\mathrm{SiC} \mathrm{ARS.} \mathrm{It} \mathrm{is} \mathrm{found} \mathrm{that} \mathrm{the} \mathrm{luminescence} \mathrm{intensity}$ 


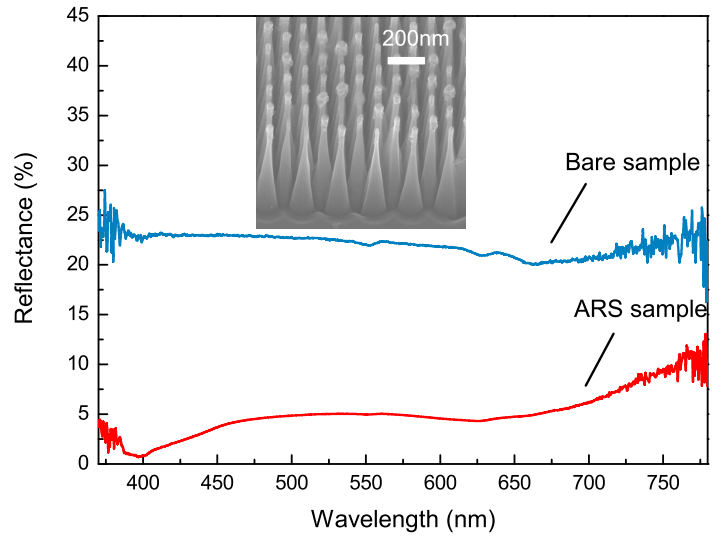

(a)

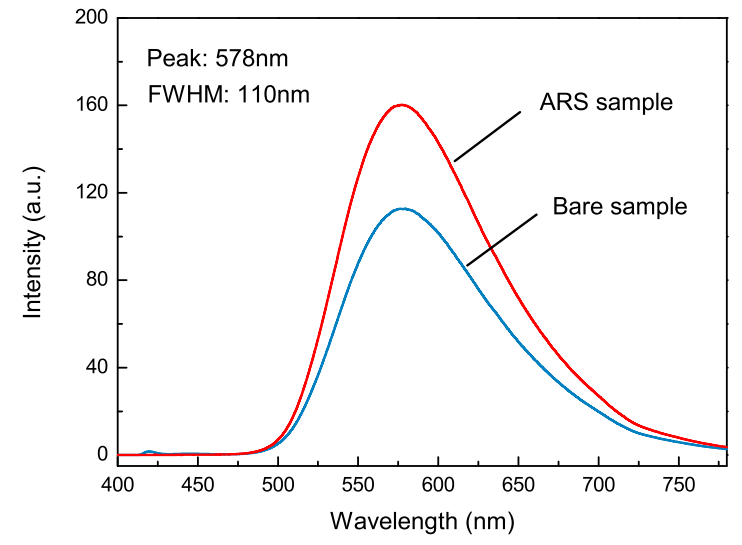

(b)

Fig. 1: (a) Reflectance curves (inset: SEM image of the SiC antireflective structures) and (b) photoluminescence spectra of the $\mathrm{SiC}$ samples with and without antireflective structures.

was dramatically enhanced as high as $41 \%$. The same peak wavelength of $578 \mathrm{~nm}$ was also observed in both spectra. In addition, the same full width at half maximum (FWHM) value of $110 \mathrm{~nm}$ was obtained which means that the ARS pattern does not change the luminescence spectral profile.

\section{Conclusion}

Antireflective sub-wavelength structures have been successfully fabricated on N-B doped fluorescent $6 \mathrm{H}-\mathrm{SiC}$ by using the reactive-ion etching method. Normal reflection at $\mathrm{SiC}$ sample surface was effectively suppressed in the spectral range from 370 to $780 \mathrm{~nm}$ which covers the entire visible range. The average reflectance decreased from $22.1 \%$ to $5.1 \%$ and the minimum reflectance of $0.69 \%$ was also obtained. From the acquired photoluminescence spectra, the DAP band luminescence intensity was dramatically enhanced by $41 \%$ after introducing the SiC ARS. Furthermore, the same spectral profile in terms of the peak wavelength and FWHM was also achieved in the fluorescent SiC sample with ARS. The experimental results indicate that ARS is an effective method to improve the extraction efficiency of the fluorescent $6 \mathrm{H}-\mathrm{SiC}$ as a wavelength converter material in the white LEDs applications.

\section{References}

1. S. Kamiyama, T. Maeda, Y. Nakamura, M. Iwaya, H. Amano, I. Akasaki, H. Kinoshita, T.Furusho, M. Yoshimoto, T. Kimoto, J. Suda, A. Henry, I. G. Ivanov, J. P. Bergman, B. Monemar, T. Onuma, and S. F. Chichibu, "Extremely high quantum efficiency of donor-acceptor-pair emission in $\mathrm{N}$-and-B-doped 6H-SiC," J. Appl. Phys. 99, 093108 (2006).

2. Y. Ou, V. Jokubavicius, S. Kamiyama, C. Liu, R. W. Berg, M. Linnarsson, R. Yakimova, M. Syväjärvi, and H. Ou, "Donor-acceptor-pair emission characterization in N-B doped fluorescent SiC," Opt. Mater. Express 1(8), 1439-1446 (2011).

3. Y. Ou, D. Corell, C. Dam-Hansen, P. Petersen, and H. Ou, "Antireflective sub-wavelength structures for improvement of the extraction efficiency and color rendering index of monolithic white light-emitting diode," Opt. Express 19(S2), A166-172 (2011).

4. M. Syväjärvi and R. Yakimova, "Sublimation epitaxial growth of hexagonal and cubic SiC," in Encyclopedia - the Comprehensive Semiconductor Science and Technology, P. Bhattacharya, R. Fornari, and H. Kamimura, eds. (Elsevier, 2011). 